\title{
IMPACT AND PERSPECTIVES ON WATER SUPPLY AND SANITATION NETWORK
}

\author{
PONÇANO, Vera Maria Lopes ${ }^{1 *}$, SILVA, Genesis Duarte de Oliveira² \\ ${ }^{1}$ Consultora Independente, Rede Metrológica do Estado de São Paulo, São Paulo, Brasil. \\ ${ }^{2}$ Bolsista CNPq, Rede Metrológica do Estado de São Paulo, São Paulo, Brasil. \\ * Corresponding author: \\ e-mail: vera.poncano@remesp.org.br
}

Received 15 June 2015; received in revised form 11 November 2016; accepted 14 December 2016

\section{RESUMO}

A Rede de Saneamento e Abastecimento de Água (RESAG) está vinculada ao Sistema Brasileiro de Tecnologia (SIBRATEC) - Serviços Tecnológicos e tem por objetivo, melhorar e ampliar, em nível nacional, a prestação de serviços tecnológicos oferecidos pelas organizações integrantes da Rede. Planejamento e ações educativas são fundamentais à solução dos problemas existentes e há ações não necessariamente, dispendiosas que podem resultar em um impacto positivo e significativo, como o advindo da aproximação e união de instituições público-privadas e vários setores tecnológicos, envolvendo muitas disciplinas do conhecimento. A gestão em forma de Rede, como a RESAG, facilita a permeabilidade e a disseminação do conhecimento nessa área nas várias regiões do País.

Palavras-chave: Saneamento e abastecimento de água, RESAG, Impacto.

\section{ABSTRACT}

The Sanitation and Water Supply Network (RESAG) is under the Brazilian Technology System Network (SIBRATEC) -Technological Services, aiming to improve and extend the technological services offered by the organizations comprised in this network. Planning and education are fundamental for the solution of the existing problems and there are actions not necessarily expensive that can result in a positive and meaningful impact, as the one coming from the approach and linkage of public and private institutions and many technological sectors, involving many discipline of the knowledge. The management in the form of a network, such as RESAG, facilitates permeability and the dissemination of knowledge in this area in the various regions of the country.

Keywords: network, quality, potability, education, planning. 


\section{REDE DE SANEAMENTO E ABASTECIMENTO DE ÁGUA}

A Rede de Saneamento e Abastecimento de Água - RESAG foi criada em 13 de abril de 2011 por representar uma das áreas estratégicas do País e está vinculada ao Sistema Brasileiro de Tecnologia - SIBRATEC no eixo dos Serviços Tecnológicos (Ministério da Ciência Tecnologia e Inovação, 2014).

\section{Contexto Geral}

Em sua primeira fase de execução, visa à consolidação da estrutura de gestão e funcionamento da Rede, com o apoio do projeto "Melhoria da Capacitação Laboratorial na área de Qualidade, Saneamento e Abastecimento de Água", aprovado pela FINEP em 13 de abril de 2011, com período de execução de 36 meses, o qual foi prorrogado para 01 de abril de 2016 (Rede de Saneamento e Abastecimento de Água, 2014b).

A RESAG em sua composição conta com a participação de 37 laboratórios de 19 institutos tecnológicos, centros universitários federais, estaduais e organizações não governamentais, localizados em 10 estados do Brasil das regiões Nordeste, Centro-Oeste, Sul e Sudeste, que realizam atividades de prestação de serviços tecnológicos especializados para atender às demandas de mercado do micro, pequenas e médias empresas (MPMEs) na área de qualidade, saneamento e abastecimento de água.

Sua organização se dá por meio de subprojetos nos temas: gestão, calibração, capacitação, programas de comparação interlaboratorial, materiais de referência certificados, acreditação, competência analítica, e caracterização de materiais para distribuição de água.

\section{Funcionamento da Rede}

Os mecanismos gerenciais adotados têm propiciado uma gestão integrada, tanto com relação aos pesquisadores e técnicos, como de suas organizações estabelecidas em diferentes regiões do País, promovendo um ambiente propício à troca e atualização do conhecimento.

As coordenações existentes na Rede funcionam de acordo com o conhecimento e responsabilidade assumida em cada função, de forma participativa, visando à obtenção de resultados de interesse comum (Castells, 1999).

Pela avaliação das atividades desenvolvidas pela RESAG até o momento, consoante com as diretrizes do SIBRATEC, observa-se que houve um desenvolvimento efetivo e o consequente aprimoramento dos serviços tecnológicos realizados pelos laboratórios participantes, bem como uma aproximação com as empresas, meio acadêmico e tecnológico. Com uma empresa foi possível, já nesse período, desenvolver um projeto conjunto na área de programas interlaboratoriais, em parâmetros químicos.

Os produtos e serviços gerados têm por meta a melhoria do desempenho dos laboratórios participantes da Rede, especialmente nos itens relacionados com o atendimento às demandas de mercado, advindas principalmente das MPMEs, que constituem a maioria dos clientes dos laboratórios participantes.

\section{IMPACTOS DECORRENTES DA FALTA DE QUALIDADE DE ÁGUA}

A falta de controle da qualidade na água de consumo humano pode acarretar problemas graves e, até mesmo, letais. A insuficiência de um efetivo saneamento básico acarreta poluição dos recursos hídricos, trazendo prejuízo à saúde da população, principalmente o aumento da mortalidade infantil, problema grave nas periferias urbanas do Brasil, além da possibilidade de transmissão de diversas doenças (Empresa Brasil de Comunicação, 2014; Agência Nacional das Águas 2014).

Com controles de qualidade adequados, que permitam o acesso à água potável e a adoção de padrões de higiene, muitas enfermidades podem ser evitadas diminuindo, também, o custo com tratamentos médicos.

O planejamento para o uso da água é, sem dúvida, importante para minimizar os impactos nos mananciais situados ao redor dos centros urbanos e os cursos de água que os atravessam. Quando não realizado, gera consequências à população, por problemas de contaminação da água, de abastecimento e irrigação, inundações frequentes, deslizamentos de encostas, erosão do solo, entre outros.

Deve-se lembrar de que, com a intensificação do grau de urbanização, ocorre um aumento na geração de resíduos, fato que 
demanda atenção específica na gestão e provoca grande impacto econômico e ambiental.

Paradoxalmente, a agricultura é considerada uma fonte de poluição das águas brasileiras. Como poderão ser cultivados produtos alimentares se a água é poluída? $\mathrm{O}$ uso eficiente e a qualidade da água na agricultura são fatores fundamentais à qualidade dos produtos gerados. Como exemplo, encontram-se os problemas de contaminação causados por agrotóxicos e fertilizantes usados nos próprios plantios, que se adicionam aos demais (Osava, 2011).

A utilização de agrotóxicos, independentemente do modo de aplicação, possui grande potencial de atingir o solo e as águas, principalmente devido aos ventos e à água das chuvas, que promovem a lavagem das folhas tratadas, a lixiviação e a erosão. Quando o terreno não possui cobertura vegetal ou quando o plantio está em sua fase inicial de crescimento, há uma maior probabilidade de contaminação dos sistemas hídricos subterrâneos. Já a plantação mais desenvolvida tem a capacidade de reter parte desta contaminação. Ademais, o deflúvio superficial e o transporte de agrotóxicos pelo ar atmosférico seriam possíveis fontes de contaminação de sistemas hídricos superficiais (Ministério do Meio Ambiente, 2014; Paraíba, 2014).

Por sua vez, na indústria, há a necessidade do uso eficiente de água para os seus processos, já que os recursos naturais são limitados. Devido aos custos elevados, associados às demandas crescentes, as indústrias têm buscado possibilidades de reúso e compra de efluentes tratados, a preços inferiores aos da captação de água potável dos sistemas públicos de abastecimento. É uma ação importante que deve ser incentivada. Os prejuízos do não tratamento e planejamento, assim como o uso ineficiente desse valioso recurso natural trazem uma consequência desastrosa a vários segmentos da própria indústria e da sociedade (Hespanhol, 2002).

A análise de contaminantes químicos não é tarefa trivial e demanda laboratórios competentes que emitam resultados analíticos confiáveis. Neste escopo, os laboratórios componentes da RESAG deverão apoiar o controle de qualidade da água, provendo resultados confiáveis à definição de ações que minimizem o impacto desses contaminantes tomando por base parâmetros existentes em normas e regulamentos e sugerindo outros, quando for necessário.

A adoção de medidas de uso racional de água na indústria e a utilização de melhores tecnologias visando ao aumento da eficiência do uso da água nas edificações residenciais são exemplos de cuidados fundamentais, que devem ser observados na gestão do uso da água. Recentemente, a própria Relatora da Organização das Nações Unidas (ONU) para o direito à água recomendou que, no Brasil, seja adotada uma estratégia segmentada que trabalhe a questão do consumo de água pelas pessoas e indústrias de forma diferente, direcionado de acordo com o perfil regional analisado. Ou seja, mesmo adotando diretrizes globais, cada país e região devem fazer o seu planejamento conforme as especificidades existentes, visando o uso mais eficiente da água (Sampaio, 2014).

Especialistas alertam que a escassez de água é uma tendência a se intensificar que poderá trazer consequências alarmantes em diversos setores, fato que se refletirá no desenvolvimento econômico nacional e, de forma mais imediata, na vida das pessoas menos favorecidas economicamente.

Os padrões internacionais existentes sugerem um consumo mínimo de 20 litros diários de água por pessoa, disponível a no máximo um quilômetro de casa. Isso seria o mínimo necessário para beber e fazer a higiene pessoal. Se for considerada a água para banho e para limpeza doméstica, a quantidade mínima sobe para 50 litros por dia. Grande parte da população mundial não tem acesso esse mínimo necessário, o que mostra que a questão da água está diretamente ligada à sua disponibilidade, à necessidade de controles da qualidade e à pobreza (Rede de Saneamento e Abastecimento de Água, 2014a).

\section{CONCLUSÕES E RECOMENDAÇÕES}

A seguir são apresentadas as conclusões e recomendações para as organizações que têm relação e influência nas tomadas de decisão, dentro da temática de saneamento e abastecimento de água, bem como contexto e orientações para a continuidade da RESAG. 


\section{Educação e Planejamento}

É fundamental a preocupação dos governos com a garantia do bem-estar e da saúde da população, com a tomada de medidas que também eduquem a comunidade para a conservação ambiental. O planejamento e as estratégias devem levar em conta uma ação ampla e efetiva, considerando todas as regiões do Brasil e as suas especificidades regionais.

A interação entre a RESAG e especialistas de organizações atuantes no tema, bem como dados de bibliografia, apontam a Educação e o Planejamento como de muita relevância na solução de problemas na área.

A adoção de medidas de uso racional da água na indústria e a utilização de melhores tecnologias para o aumento da eficiência de seu uso em edificações e residências são exemplos de cuidados a serem observados na gestão do uso da água. Existem ações, não necessariamente dispendiosas, que podem resultar em um impacto significativo ao país, cuja gestão depende, basicamente, de treinamento e capacitação. Como exemplo, as práticas de uso e reúso da água em diversos níveis e situações são ainda muito restritas e poderiam ser alvo de ação em programas multidisciplinares educativos.

O abastecimento de água potável, o saneamento adequado, o tratamento de esgoto, a limpeza urbana, o manejo de resíduos sólidos e drenagem das águas pluviais representam o conjunto de serviços de infraestrutura e instalações operacionais que podem melhorar a vida da população. Porém, para a sua real consecução são necessárias ações de planejamento por parte do governo, em diferentes níveis regionais e nacional e o envolvimento dos diversos segmentos da sociedade vinculados ao tema.

É importante o desenvolvimento de programas para intensificar a conscientização da sociedade sobre o uso adequado da água e sua relação com a saúde e meio ambiente. Como exemplo, as práticas de uso e reúso da água em diversos níveis e situações são ainda muito restritas e poderiam ser alvo de ação multidisciplinar educativa.

\section{Qualidade da água}

A contaminação das fontes de água doce naturais está resultando em um passivo ambiental elevado, que colocam em perigo os ecossistemas terrestres. $O$ crescimento da população urbana, a expansão da produção agrícola, o uso industrial não eficiente da água, a carência de ações educativas e a falta de saneamento, entre outros fatores, têm conduzido a uma situação extremamente preocupante. Todos os esforços possíveis devem ser feitos para manter e controlar a qualidade de água doce.

\section{RESAG}

A RESAG nesta primeira etapa vem estabelecendo o seu processo de gestão, de forma que este tenha a solidez adequada à sua ampliação, com a incorporação de novos laboratórios de outras instituições e regiões do País, bem como novas linhas de atuação estratégicas principalmente nas áreas discutidas neste trabalho.

As sinergias geradas entre os partícipes da RESAG nesta formatação de rede, bem como os desenvolvimentos já realizados, propiciam a elaboração de projetos coletivos, cujos resultados deverão ser superiores em relação às atuações individuais das instituições membros, gerando um reflexo ampliado no País (Ponçano, 2005; Ponçano et al., 2004).

A consolidação da infraestrutura laboratorial adequada nas diversas regiões do País é um dos principais objetivos da RESAG. O impacto dessa ação será percebido diretamente nas condições de controle da qualidade da água de consumo humano e os demais tipos utilizados para outras finalidades. O controle de qualidade da água nos parâmetros físicos, químicos e físico-químicos também será relevante às medidas de saneamento que sejam executadas.

Existe um entrelaçamento entre a função de serviços tecnológicos e as funções de normalização, regulamentação técnica, avaliação da conformidade (inspeção, certificação, ensaios, etc.), metrologia, informação tecnológica, propriedade industrial e outras relacionadas, que se constituem nos alicerces da Tecnologia Industrial Básica (TIB). $\mathrm{Na}$ prática, para um atendimento mais completo e orientativo às MPMEs e outros segmentos da 
sociedade, o eixo de serviços tecnológicos deve estar bem articulado com as demais funções da tecnologia industrial básica, em sustentação à infraestrutura da qualidade nacional. Esse fato foi observado em solicitações advindas de pequenas empresas, que precisavam de medições e também de normas, avaliação de conformidade, etc. para poder ter o seu produto comercializado. Existe uma falta de visão de conjunto dos fundamentos dos elementos necessários a esses desenvolvimentos e também dificuldades na obtenção das informações.

A disseminação da cultura e as atividades educativas também devem ser foco de atenção e planejamento nas fases subsequentes da RESAG.

\section{Atuação em Rede}

Atuações cooperativas como Redes são especialmente benéficas em função da diversidade de demandas que podem ser atendidas por meio de ações complementares entre seus participantes, com sistemas nos quais as demandas podem ser resolvidas em prazos menores e com menos investimentos, numa conjugação de competências, tanto em recursos humanos como em infraestrutura material e institucional existentes no País.

Redes de cooperação competitivas como a RESAG devem atuar como um instrumento de melhoria e potencialização entre os seus intervenientes e destes com o mercado, por meio do qual se pretende maximizar o retorno advindo da atividade desenvolvida em cooperação.

\section{União de esforços}

O atendimento das demandas da sociedade no tema de saneamento e abastecimento de água requer ações articuladas entre vários segmentos tecnológicos, dada a multidisciplinaridade das áreas do conhecimento envolvidas, o que pode ser resolvido utilizando a permeabilidade de redes como a RESAG e outras que existam.

Desenvolvimentos conjuntos e coordenados no País que considerem as múltiplas dimensões da questão da água, como a ambiental, política, técnica, científica, social, ética, cultural, educativa, econômica e geográfica, com a consolidação de políticas ativas de desenvolvimento sustentável, terão reflexos na qualidade de vida da população e no futuro de nossa sociedade.

Todos e cada um de nós - cidadãos, políticos, industriais, pesquisadores, dentro de sua linha de ação, responsabilidade e possibilidade, pode contribuir para preservar este recurso valioso, que é a água, começando pelo consumo sem desperdício e evitando poluir. É compromisso da RESAG fazer o que estiver ao seu alcance, para contribuir de maneira concreta e efetiva nas temáticas relacionadas com esse recurso vital - Água.

Como disse Madre Teresa de Calcutá: "Por vezes sentimos que aquilo que fazemos não é senão uma gota de água no mar. Mas o mar seria menor se lhe faltasse uma gota".

\section{AGRADECIMENTOS}

Agradecemos ao Ministério de Ciência, Tecnologia e Inovação (MCTI), à Financiadora de Estudos e Projetos (FINEP) e ao Conselho Nacional de Desenvolvimento Científico e Tecnológico (CNPq) pela iniciativa da criação da RESAG e pelo apoio que tem propiciado ao seu desenvolvimento; aos colegas da RESAG que têm tornado essa atividade produtiva $e$ gratificante e à equipe de apoio - secretáriaexecutiva e bolsistas - pela constante colaboração.

\section{REFERÊNCIAS}

1. AGÊNCIA NACIONAL DAS ÁGUAS ANA. Programa Nacional de Avaliação da Qualidade das Águas.http://www2.ana.gov.br/Paginas/p rojetos/QualidadeAgua.aspx. Acesso em: out. 2014.

2. Castells, M.A. Sociedade em rede. 2. ed. Paz e Terra: São Paulo, 1999.

3. EMPRESA BRASIL DE COMUNICAÇÃO - EBC. Falta de água de qualidade mata uma criança a cada 15 segundos no mundo, revela Unicef. http://www.ebc.com.br/noticias/brasil/20 13/03/falta-de-agua-de-qualidade-matauma-crianca-a-cada-15-segundos-nomundo. Acesso em: out. 2014. 
4. Hespanhol, I. Revista Brasileira de Recursos Hídricos. 2002, v.7, n.75.

5. Ministério da Ciência Tecnologia e Inovação. Apresentação Sibratec, $<$ http://www.mct.gov.br/index.php/conten t/view/313014.html. Acesso em: out. 2014.

6. Ministério do Meio Ambiente; Agrotóxicos, http://www.mma.gov.br/segurancaquimica/agrotóxicos, acessada em outubro 2014.

7. Osava, M. Controle-da-qualidade da agua o Brasil não acompanha contaminação química. Jornal do Brasil, 25 jul. 2011. http://www.jb.com.br/ciencia-eecnologia/noticias/2011/07/25/controleda-qualidade-da-agua-no-brasil-naoacompanha-contaminacao-quimica/. Acesso em: out. 2014.

8. Paraiba, L. C. et al. Span J Agric Res. 2014, 12, 509.
9. Ponçano, V. M. L. Anais da $35^{\mathrm{a}}$ Seminário Temático da Anvisa, Brasília, Brasil, 2005.

10. Ponçano, V. M. L.; D’Almeida, M. L. O.; Makiya, I. K.. Anais da $4^{\mathrm{a}}$ Congresso Latino-Americano de Metrologia, Foz do Iguaçu, Brasil, 2004.

11. Rede de Saneamento e Abastecimento de Água, http://www.resag.org.br/informacoes-eestatisticas/saneamento-abastecimento. Acesso em: out. 2014b.

12. Rede de Saneamento e Abastecimento de Água. Objetivos da criação. http://www.resag.org.br/resag, Acesso em: out. 2014a.

13. Sampaio, L. Falta de água é culpa do governo de SP, afirma relatora da ONU. Folha de São Paulo 31 ago. 2014. http://www1.folha.uol.com.br/cotidiano/2 014/08/1508504-falta-de-agua-e-culpado-governo-de-sp-afirma-relatora-daonu.shtml. Acesso em: out. 2014. 